\title{
A great schism approaching? Towards a micro and macro public administration
}

\section{Donald Moynihan*}

\begin{abstract}
As an emerging field, behavioral public administration (BPA) has spurred important new research, documenting human biases and heuristics in public sector contexts. In doing so, it has embraced Herbert Simon's call to draw from psychology to understand administrative behavior. To fulfill its potential, BPA should also pursue another goal of Simon: a normative aspiration toward design science, using its powerful analytical techniques to solve, and not just document, real administrative problems. Another challenge for BPA is understanding where it fits in the constellation of public administration research. One critique of BPA is that a focus on micro-level behavior leads to a neglect of big questions that were once central to public administration. But this tension may also signal the possibility of a productive division of labor, with a micro and macro public administration that addresses distinct questions, but which are connected by common research concepts.
\end{abstract}

Keywords: Design, Administrative behavior, Experiments, Public administration

B ehavioral public administration (BPA) has been defined as focusing on micro-level behavioral processes (how we develop preferences and make choices) within the context of public services, and it draws strongly both from psychological theories and from the experimental approach favored by that discipline (see Grimmelikhuijsen et al., 2017 for a more detailed explanation). The International Research Society for Public Management, the European Group of Public Administration, and the Public Management Research Conference have organized workshops or panel tracks specifically devoted to behavioral public administration, and we have seen symposia on both BPA and experiments in top public administration journals. The new journal in which this essay appears is another milestone in the growth of BPA. In this respect BPA is not just an approach to generating knowledge, but also a mechanism for branding knowledge (signaling rigor to its adherents) and networking among like-minded scholars.

\footnotetext{
* The Robert M. La Follette School of Public

Affairs, University of Wisconsin-Madison

Address correspondence to Donald Moynihan at (dmoynihan@lafollette.wisc.edu)

Copyright: (C) 2018. The author licenses this article under the terms of the Creative Commons Attribution 4.0 International License.
}

In early November of 2016, I joined a small meeting about BPA at the Dutch Royal Academy of Arts and Sciences. My assigned role in Amsterdam was to be a devil's advocate-that is, to critique and puncture groupthink. In reviewing candidates for sainthood, the Catholic Church used to appoint a lawyer who would offer objections from Satan's perspective, Satan himself not being directly available. Such was my role, which I undertook despite the fact that much of my own work seeks to explain administrative behavior and that I have grown very fond of using experiments. I was forced to set aside my priors, which are that BPA is generating very good research.

In my own area of performance management, the progress over the last decade has been nothing short of astounding. My early work identified performance information use as a key dependent variable (Moynihan \& Ingraham, 2004) and, by 2010, I had argued that this merited a behavioral approach (Moynihan \& Pandey, 2010). The emergence of BPA fueled new insights on how individuals (especially citizens) process performance data, and work in this area has been theoretically richer and empirically more rigorous than what has come before (e.g. James, 2011; James et al., 2016; James \& Moseley, 2014; James \& Van Ryzin., 2016; Nielsen \& Baekgaard, 2015; Marvel, 2015; Olsen, 2015; Olsen, 2016). If we need proof of concept for the 
virtues for BPA, the field of performance management is an excellent place to start. From my admittedly biased perspective, the study of performance management has become perhaps the most interesting subfield within public administration, evolving from a repetitive but incomplete account of why reforms fail to a compelling investigation of how people in organizations make sense of information. Without BPA, such progress would not have been made so quickly, if at all.

As any good BPA scholar will guess confirmation bias kicked in once I was assigned my task of critiquing the potential risks of BPA (even as it forced me to acknowledge these critiques apply as much to my own work as to the work of others). I also, at the time of the Amsterdam meeting, wore the hat of president of the Public Management Research Association, and tried to consider what the movement will mean for the field of public administration as a whole. While it might seem that the launch of a new Journal of Behavioral Public Administration (JBPA) is perhaps not the occasion to consider the negative aspects of this approach, I take some heart in the knowledge that BPA's dedication to transparency and the self-criticism implied by replication will allow me to offer some critical observations without causing too great offense. Indeed, I welcome replies and hope my comments below spark a constructive dialogue in the future pages of JBPA.

\section{What is BPA Rebelling Against?}

A starting point for my critique is the self-conscious echo between "behavioral public administration" and "behavioral economics." The context of economics is quite different from public administration in a way that matters for how we situate BPA as either an evolution or revolution within the field. In economics, a behavioral approach was needed to puncture the assumption of rationality that had overtaken that discipline, but which was never widely accepted beyond economics. Richard Thaler (2016, p. 1579) argues that economics itself was once more open to understanding the vagaries of human behavior, but by the middle of the 20th century an idealized model of Homo Economicus had taken hold, characterized by well-defined exogenous preferences, self-interest, and optimal decision-making skills: "In the process of making economics more mathematically rigorous after World War II, the economics profession appears to have lost its good intuition about human behavior...Economics textbooks no longer had any Humans. How did this happen? I believe that the most plausible explanation is that models of rational behavior became standard because they were the easiest to solve."

Despite the efforts of public choice theorists, public administration never embraced Homo Economicus. The post-World-War II period was more focused on grappling with the reality that politics could not be neatly separated from administration. Political science dominated the field, leaving both the formalizing path of economics and the humanizing path of psychology untaken. Models of rationality, when they appeared at all, mostly served as straw men to illustrate that behavior was the product of beliefs and motivations that were not completely rational, and that preferences were endogenous to the context in which people found themselves. Reading Wildavsky's assessment of the budget process or Lindblom's insights on muddling through, one sees a world of actors pursuing a complex array of beliefs shaped by institutional loyalties, and using heuristics to manage cognitive loads. Put another way, public administration did not need Herbert Simon in the same way economics did-because it already had Simon.

Like the Molière character who discovers he has "been speaking prose all my life, and didn't even know it!", some of us who had been doing behavioral research, but not using those terms, woke up one day to find that we had become good behavioralists. Of course, it is a different and very fair question to ask whether we made very good use of Simon's insights (Olsen, 2015). In particular, the use of psychology to build micro-foundations of administrative behavior has been done haphazardly, if at all (Grimmelikhuijsen et al., 2017). Simon and other scholars who actually observed administrators offered enough of an antidote against Homo Economicus, though not enough to offer a clearly defined path for public administration, a field that has constantly struggled with its identity. BPA might be seen as a belated effort to uncover that path and turn it into a highway.

\section{Big Questions Neglected? Or a New Division of Labor?}

Another concern with the BPA movement is that it might detract attention from "big questions." A number of scholars have made the argument that 
public administration has lost sight of fundamental questions of how the state should be designed to withstand the challenges of the day, questions that preoccupied previous generations of public administration scholars (Milward et al., 2016; Roberts, 2017a; Roberts, 2017b). Such questions are certainly salient: the nation-state seems to lack the capacity to address fundamental challenges such as climate change. The 20th century faith in bureaucracy that characterized the most dominant period of public administration scholarship seems a distant memory, as the legitimacy of non-partisan expertise is increasingly under challenge, often from the very people elected to lead the bureaucracy (Moynihan \& Ingraham, 2010).

As a field, public administration has always studied people, organizations, and institutions, and of late we have expanded our remit to incorporate networks. The implicit criticism of the "big questions" adherents is that by focusing only on individuals, BPA is augmenting a trend in the field to neglect these other units of analysis and related variables, such as political power. One participant at the Amsterdam meeting critiqued the current behavioral economics "nudge" movement on these grounds, pointing out that we focus on micro-level nudges while ignoring macro "shoves" such as a large-scale redefinition of the welfare state or vast inequities in the distribution of political power across groups.

A very reasonable response to this critique, familiar to countless authors told by a reviewer that they should have written a different paper on another topic, is to say: "If you think the big questions are so damn important, go study them yourself?" With that said, the field of public administration is a small one, with a finite amount of scholarly firepower. Opportunity costs in the choice of study are real: if many of our most talented scholars choose to study X, there will be less attention to Y.

Another response to the big-questions critique is that the micro-foundations of administrative behavior are themselves big questions. After all, a central goal of psychology is to uncover widespread human patterns of attention, perception, information-processing and decision-making. Are these not big questions? The abstraction of such patterns in the discipline of psychology may make them feel distant from any particular applied setting, but the ambition is to offer explanatory power across time and context. If BPA succeeds in apply- ing these basic insights to better illuminate the human side of public administration, it would certainly seem like a significant achievement and one with practical implications. For example, we surely gain a better handle on understanding administrative reforms by having a firm grasp on the likely behavioral responses to the reform rather than looking at what happened during the last reform.

Questions on the state of the state are, or at least should be, big questions for the field of public administration (PA). If we accept that behavioral questions are also big questions, where does that leave us? The answer, if would seem, is either an accommodation between BPA and the big-questions perspectives or an intellectual rivalry. Taking the first path, we could move toward a micro and macro public administration, where the micro public administration focuses on behavioral questions and the macro public administration focuses on institutional questions. We could accommodate this division of labor amicably by acknowledging that both approaches are legitimate-though their approaches to studying each topic differ-and that micro knowledge can inform macro questions of statecraft. Or, following the other path, we could allow a less amicable divorce marked by each group selecting into different journals, panel tracks and even conferences. To some degree, this is already happening.

The logic of micro and macro public administration may seem so obvious as to appear inevitable. After all, economics uses this approach to solve its division of labor problem. A micro and macro public administration would sidestep normative issues of what are worthwhile and relevant research questions to put us on a more neutral terrain, where different questions simply reflect different levels of analysis, correlating with different methodological techniques. But let me offer some notes of caution. Microeconomics and macroeconomics are largely separate subfields within economics, and fruitful interaction between the two is rare. So, a micro and macro public administration may serve as a division of labor, but of what type remains unclear. Perhaps we will specialize in different steps of the same production process, such as the workers in Adam Smith's pin factory that generate efficiencies through specialization. Or perhaps we will be more like different shops selling different products, unified only by being perceived as operating in the same shopping mall. Or most worryingly, the correct metaphor may be the great 
schism, where Protestant reformers chose to break away from Rome, setting off centuries of tensions between groups who were nominally all Christian.

To be productive, a connection between micro and macro approaches requires bridging concepts that can connect the two. The easiest example that comes to mind from my own work is the concept of administrative burden. Here the concept rests on micro-foundations from psychology, including that people struggle to weigh shortterm costs relative to long-term gains, that they often fail to overcome small immediate barriers to achieve those gains, and that reframing default options has a profound effect on decision-making (Moynihan, Herd, \& Harvey, 2015). At the same time, the concept also speaks to how state capacity is needed to design and implement basic mastery of the tasks that are important to citizens, something we often take for granted in liberal democracies, becoming a crisis only in its absence (Roberts, 2017a). Such concepts offer a means to build conversations between scholars in micro and macro public administration.

\section{Methodolotary}

A related risk to the big-questions critique is that of the worship of a single methodological technique methodolotary, if you will - may have the effect of narrowing the range of questions researchers address. So how might methodolotary affect BPA? Here, the dominant technique is the experiment, valued for its ability to offer causal insights. The BPA movement can be credited with revitalizing this long-known but rarely used approach in public administration (see James, Jilke, \& Van Ryzin, 2017 for a summary). An over-reliance on experiments, however, can blind us to their limits in terms of the evidence they produce, while directing attention only to those questions that are most easily answered by experimental designs. We risk becoming the man searching for his keys under a streetlight, not because he lost them there but because that's where its easiest to search.

Scholars, including Nobel laureates James Heckman and Angus Deaton, have offered detailed critiques of the limits of experiments. For example, Heckman's study of performance standards in job training programs, which incorporated questions of administrative use of performance data and discretion, led him to conclude: "Since experiments can answer only a subset of the questions of interest to evaluators, it remains important to build up the stock of basic social science knowledge required to successfully utilize nonexperimental methods, both by themselves and as a tool for more extensive analyses of experimental data" (Heckman \& Smith, 1995, p. 95). Deaton and Cartwright (2016) also caution about the zeal for experiments, noting that they are no substitute for theory, and that it is hard to infer insights beyond their original context. The natural limits for external generalizability from experiments means that the accumulation of knowledge comes not from any particular study in a specific setting, but from multiple experiments in multiple settings (Angrist \& Pischke, 2010).

A reliance on experiments may also serve to exclude important questions. The pursuit of clear causal identification raises such a concern within economics. Raj Chetty, one of the most influential voices in contemporary economics, noted: "People think about the question less than the method. They're not thinking 'what important question should I answer.' So you get weird papers, like sanitation facilities in Native American reservations" (quoted in Scheiber, 2008, p. 29). Within public administration, many topics raise important questions that do not lend themselves to experiments. To return to the example of administrative burdens, the subject yields many relevant behavioral questions about how psychological factors affect citizen-state interactions but also highlights issues that can best be narrated using an observational approach, such as the role of politics and power in the deliberate creation of these burdens in real policy settings. An approach that privileges technique to the point that important substantive questions are excluded, even if inadvertently, weakens our ability to develop a comprehensive understanding of administrative topics. A more pluralistic approach is consistent with the broader methodological toolbox of psychology, which has devoted significant scholarly attention to descriptive tools, such as validated scales of personality, incentivized measures of altruism, and various indirect ways of capturing individual differences in implicit bias or dishonesty. Such tools are obviously relevant to public administration. For example, the study of administrative burdens could also offer relevance and rigor by using descriptive approaches to map differences in the psychological costs that different groups of citizens face when they encounter different types of interactions with the state. 
To return to the field of performance management, experiments have been deployed to great effect in identifying how numerical illiteracy and cognitive biases-most obviously a negativity bias and motivated reasoning-undercut people's ability to process information when judging public institutions (Baekgaard \& Serritzlew, 2016; James \& Van Ryzin, 2017; Marvel, 2016; Nielsen \& Moynihan, 2017). Taken too far, a single-minded focus on biases can itself become a bias of sorts, leading to a misunderstanding of the balance between rationality and heuristics. If nine of every ten articles on performance information document biases, one could be forgiven for concluding that irrationality is the essential condition of human behavior, leading to conclusions such as Andrew Ferguson's (2015): "People's attitudes and opinions are not the consequence of argument or experience, research revealed, but rather of unreasoning bias and emotion." Perhaps I remain overly-optimistic about the human condition, but this strikes me as wrong, leading to a "dismissal of human rationality and human agency in the political arena" (Gelman, 2015). Even as Herbert Simon warned us of cognitive limitations, he balanced that warning with a portrayal of administrators as intendedly rational, working in goal-oriented organizations.

\section{Combining BPA and Design Science}

An exclusive focus on cognitive biases may also displace attention to another charge of Simon: to become a design science that offers useful guidance about how to create processes, incentives, and structures in a way that generates optimal outcomes. This charge gets directly to the purpose of public administration. It is entirely reasonable to ask whether societal resources should be devoted to an applied field if it is not producing actionable knowledge. Thus far, BPA has not passed this test with flying colors. In this, BPA is not that dissimilar to much of the rest of public administration research (Nesbit et al., 2011).

The failure to become a design science may again be partly a function of the techniques employed. After all, it is difficult to experimentally model many variables that observational studies suggest are important, such as organizational culture. This weakness may also reflect an over-reliance on psychology, which has developed compel- ling theories for biases but given us much less guidance on how to overcome them in an applied setting.

The way in which BPA may have the greatest positive impact is to embrace both Simon's charge to draw from psychology to understand administrative behavior (Olsen, 2015) and his call to design for better administrative outcomes (Barzelay \& Thompson, 2010). At some point continuing to document biases in an administrative setting that psychology has already covered will lead to declining marginal returns. Our value as an applied field will be using psychology to design ways to overcome biases and improve outcomes.

It is already possible to spot a few actionable insights along these lines. For example, we can feel relatively confident that presenting information in a positive rather than negative valence reduces negativity bias (Olsen, 2015), and that giving managers comparative performance data makes it more likely that they will pay attention to performance (Andersen \& Moynihan, 2016; Olsen, 2017). Such insights, however, too often appear as afterthoughts tucked into the conclusion of research papers. What is needed is the same self-conscious, determined elevation and pursuit of design as a central value that we have seen in behavioral economics, where the "nudge" approach has emphasized solving problems rather than just documenting them.

One shortcoming of the nudge approach is the emphasis on the limits of human cognition, where choice architecture is largely centered on compensating for biases. An even more optimistic approach to design science can be found in the "boosting" model, which focuses on improving human competences with domain-specific skills, knowledge, or decision tools that equip people to make informed decisions (Hertig \& Grüne-Yanoff, 2017). For an applied field where scholars directly train public servants and have the opportunity to work collaboratively with governments, the ethos of boosting offers a positive model for interventions, one that demands deep knowledge of the public sector and more ingenuity than simply applying insights from psychology.

To return to the area of performance management, research could move beyond documenting biases to designing and testing interventions that result in more deliberative reasoning. For example, observational data suggest that structured routine reviews of goals lead to more purposeful 
use of performance data (Moynihan \& Kroll, 2016), but without rigorous testing of the causal processes that make learning forums work. Design science can be pursued through survey experiments. For example, is it possible to frame information in a way that dampens biases from such influences as political ideology (Baekgaard et al., 2017)? Some questions require field experiments or other techniques that include altering basic organizational or institutional conditions in which people are embedded. Some of this work should also come from non-experimental methods. Within economics, the empirical study of policy questions has gained credibility partly through better designed experiments, but also through the growing availability of more and better administrative data together with better quasi-experimental techniques (Angrist \& Pischke, 2010). As suggested in the above discussion of administrative burdens, investigation can also be pursued using descriptive techniques, such as using a psychological lens to document the types of costs people experience in their interactions with the state.

\section{Diversity and Homogeneity in Knowledge Generation}

A final consideration for the behavioral PA movement is centered on how diversity and homogeneity are related to knowledge creation. More homogenous groups enjoy lower friction and transaction costs, and work more quickly. More diverse groups encounter more conflict and slower work processes, but ultimately generate better decisions, especially for complex tasks (Page, 2007). Understanding tradeoffs between homogeneity and diversity is relevant because, in its effort to establish itself, BPA has generated a certain type of homogeneity.

BPA categorizes work not by substantive area but by whether or not it is behavioral. Scholars at conferences are faced with practical choices about whether they go to the BPA track or their substantive research interest. This point hit home to me as I sat in the public personnel section in the European Group of Public Administration in Utrecht in 2016. Attendees were expected to stick with a single track throughout, and I was sorry I could not also attend the BPA track. This made me wonder how this separation of BPA from substantive topics would affect knowledge generation in public administration more generally. The personnel section would have benefited from BPA's knowledge of psychology and modeling suggestions, and I can't help but think the BPA track missed out on some of the theoretical insights that arise when a group of smart people sit in a room and focus intently on addressing one substantive area they know a lot about for a sustained amount of time.

\section{Conclusion: BPA will Succeed by Making Itself Redundant}

An appropriate response to the above concerns is that BPA is still in its infancy and needs to establish an identity and convert a critical mass of adherents if it is to have sustained impact. For now, the benefits of homogeneity may be precisely what is needed. I can't fault this argument, but it begs a follow-up question: When does the incubation period end? Is it ten years? Five years? Less? More? My sense is that the BPA movement is already immensely strong, and the point is fast approaching when the benefits of diversity for knowledge generation will outweigh the current virtues of homogeneity.

The best measure of BPA's success may be if it ultimately puts itself out of business. Its goal must be not to rebel against the field of public administration but to become embedded within the establishment, such that any scholar studying individual behavior will be using the tools and techniques of BPA without feeling the need to label it as such. The same goal has been urged upon behavioral economics, with Chetty (2015) proposing that it is increasingly less useful to divide the field between neoclassical versus behavioral perspective, but instead behavioral insights should displace older approaches where they offer greater insights. Richard Thaler (2016, p. 1597), the first behavioral Nobel Prize winner to actually emerge from economics, is even more explicit:

"There is nothing unique about incorporating psychological factors such as framing, self-control, and fairness into economics analyses. If such factors help us understand the world better and improve predictions about behavior, then why wouldn't we use them just like we would use any other new source of data such as web searches or genetic markers? In this sense, I think it is time to stop thinking about behavioral 
economics as some kind of revolution. Rather, behavioral economics should be considered simply a return to the kind of open-minded, intuitively motivated discipline that was invented by Adam Smith and augmented by increasingly powerful statistical tools and datasets. This evidence-based discipline will still be theoretically grounded, but not in such a way that restricts our attention to only those factors that can be derived from our traditional normative traditions...If economics does develop along these lines the term "behavioral economics" will eventually disappear from our lexicon."
If we are still treating behavioral public administration as a distinct subfield a decade from now, it will have failed to fully deliver on its current enormous promise. If its techniques have become embedded in the standard approaches by which we consider some of our core research questions, it will have succeeded. One benchmark: Will this new journal attract people who do not identify primarily as BPA scholars, but rather see themselves chiefly as examining substantive topics that fall under micro public administration? I look forward to checking back in a decade to find out the answer.

\section{References}

Angrist, J. D., \& Pischke, J. S. (2010). The credibility revolution in empirical economics: How better research design is taking the con out of econometrics. The Journal of economic perspectives, 24(2), 3-30.

Andersen, S. C., \& Moynihan, D. P. (2016). Bureaucratic investments in expertise: Evidence from a randomized controlled field trial. The Journal of Politics, 78(4), 1032-1044.

Barzelay, M., \& Thompson, F. (2010). Back to the future: making public administration a design science. Public Administration Review, 70, S295-S297.

Baekgaard, M., \& Serritzlew, S. (2016). Interpreting performance information: Motivated reasoning or unbiased comprehension. Public Administration Review, 76(1), 73-82.

Baekgaard, M., Christensen, J., Dahlmann, C. M., Mathiasen, A., \& Petersen, N. B. G. (2017). The role of evidence in politics: Motivated reasoning and persuasion among politicians. British Journal of Political Science, doi:https://doi.org/10.1017/S0007123417000084.

Chetty, R. (2015). Behavioral economics and public policy: A pragmatic perspective. The American Economic Review, 105(5), 1-33.

Deaton, A., \& Cartwright, N. (2016). Understanding and misunderstanding randomized controlled trials (No. w22595). National Bureau of Economic Research.

Ferguson, A. (2015). Big (phony) data. The Weekly Standard. Retrieved from http://www.weeklystandard.com/big-phonydata/article/952627

Gelman, Andrew. 2015. No, public opinion is not driven by 'unreasoning bias and emotion' Monkey Cage, Retrieved from https://www.washingtonpost.com/news/monkeycage/wp/2015/05/28/please-dont-let-me-bemisunderstood/
Grimmelikhuijsen, S., Jilke, S., Olsen, A. L., \& Tummers, L. (2017). Behavioral public administration: Combining insights from public administration and psychology. Public Administration Review, 77(1), 45-56.

Heckman, J. J., \& Smith, J. A. (1995). Assessing the case for social experiments. The Journal of Economic Perspectives, 9(2), 85-110.

Hertwig, R., \& Grüne-Yanoff, T. (2017). Nudging and boosting: Steering or empowering good decisions. Perspectives on Psychological Science, 12(6), 973986.

James, O. (2010). Performance measures and democracy: Information effects on citizens in field and laboratory experiments. Journal of Public Administration Research and Theory, 21(3), 399-418.

James, O., Jilke, S., Petersen, C., \& Van de Walle, S. (2016). Citizens' blame of politicians for public service failure: Experimental evidence about blame reduction through delegation and contracting. Public Administration Review, 76(1), 83-93.

James, O., \& Moseley, A. (2014). Does performance information about public services affect citizens' perceptions, satisfaction, and voice behaviour? Field experiments with absolute and relative performance information. Public Administration, 92(2), 493-511.

James, O., Jilke, S. R., \& Van Ryzin, G. G. (Eds.). (2017). Experiments in public management research: Challenges and contributions. Cambridge University Press.

James, O., \& Van Ryzin, G. G. (2016). Motivated reasoning about public performance: An experimental study of how citizens judge the affordable care act. Journal of Public Administration Research and Theory, 27(1), 197-209.

Marvel, J. D. (2015). Unconscious bias in citizens' evaluations of public sector performance. Journal of Public Administration Research and Theory, 26(1), 143158. 
Milward, B., Jensen, L., Roberts, A., Dussauge-Laguna, M. I., Junjan, V., Torenvlied, R., Boin, A, Colebatch, H.K., Kettl, D., \& Durant, R. (2016). Is public management neglecting the state? Governance, 29(3), 311-334.

Moynihan, D., Herd, P., \& Harvey, H. (2014). Administrative burden: Learning, psychological, and compliance costs in citizen-state interactions. Journal of Public Administration Research and Theory, 25(1), 4369.

Moynihan, D. P., \& Ingraham, P. W. (2004). Integrative leadership in the public sector: A model of performance-information use. Administration \& Society, 36(4), 427-453.

Moynihan, Donald P., and Patricia W. Ingraham. 2010. "The suspect handmaiden: The evolution of politics and administration in the American state." Public Administration Review 70(S1): 229-237.

Moynihan, D. P., \& Kroll, A. (2016). Performance management routines that work? An early assessment of the GPRA Modernization Act. Public Administration Review, 76(2), 314-323.

Moynihan, D. P., \& Pandey, S. K. (2010). The big question for performance management: Why do managers use performance information?. Journal of public administration research and theory, 20(4), 849-866.

Nesbit, R., Moulton, S., Robinson, S., Smith, C., DeHart-Davis, L., Feeney, M. K., ... \& Hou, Y. (2011). Wrestling with intellectual diversity in public administration: Avoiding disconnectedness and fragmentation while seeking rigor, depth, and relevance. Journal of Public Administration Research and Theory, 21(suppl_1), i13-i28.

Nielsen, P. A., \& Moynihan, D. P. (2017). How do politicians attribute bureaucratic responsibility for performance? Negativity bias and interest group advocacy. Journal of Public Administration Research and Theory, 27(2), 269-283.

Olsen, A. L. (2015). Citizen (dis) satisfaction: An experimental equivalence framing study. Public Administration Review, 75(3), 469-478.

Olsen, A. L. (2015). "Simon Said," We Didn't Jump. Public Administration Review, 75(2), 325-326.

Olsen, A. L. (2017). Compared to what? How social and historical reference points affect citizens' performance evaluations. Journal of Public Administration Research and Theory, 27(4), 562-580.

Page, S. E. (2008). The difference: How the power of diversity creates better groups, firms, schools, and societies. Princeton University Press.

Roberts, A. (2017a). Four Crises of Democracy. Oxford: Oxford University Press.

Roberts, A. (2017b). The aims of public administration: Reviving the classical view. Perspectives on Public Management and Governance, https://doi.org/10.1093/ppmgov/gvx003
Scheiber, N. (2007). Freaks and geeks. The New Republic. 2: 27-31.

Thaler, R. (2016). Behavioral economics: Past, present and future. American Economic Review. 106(7): 15771600 . 